\title{
Optical Analysis of Ag-NPs Containing Methyl Ammonium Lead Tri- lodide Thin Films
}

\author{
Cliff Orori Mosiori ${ }^{1}$, Walter Kamande Njoroge ${ }^{2}$, Lawrence Otieno 0 choo ${ }^{2}$ \\ ${ }^{1}$ Technical University of Mombasa \\ P. 0. Box 90420-80100, Mombasa, Kenya \\ ${ }^{2}$ Kenyatta University \\ P. 0. Box 43844-00100, Nairobi, Kenya
}

DOI: $10.22178 /$ pos.26-10

LCC Subject Category:

TP155-156, QC450-467, QD450-801

Received 12.07.2017

Accepted 12.09.2017

Published online 30.09.2017

Corresponding Author:

corori@tum.ac.ke

(C) 2017 The Authors. This article is

licensed under a Creative

Commons Attribution 4.0 License

\begin{abstract}
Methyl ammonium lead tri-iodide hybrid thin films were grown using solution technique. They were doped with silver nano-particles at different concentrations at concentrations of $0.05,0.06,0.07,0.08$, and $0.09 \mathrm{mM}$. Their reflectance and transmittance were recorded in the wavelength range 300-900 using UV-Vis double - beam spectrophotometer. Using these measurements, other optical parameters were simulated using scout software. The effect of silver nanoparticles was investigated. Results revealed that the thin films had highest transmittance of about $79 \%$ as their band gap varied from 1.921-1.832 eV. Electrical conductivity varied from $1.4-1.6 \times 10^{5} \mathrm{~S} \mathrm{~cm}^{-1}$ while optical conductivity varied in the range of $0.3-$ $0.6 \times 10^{10} \mathrm{sec}^{-1}$. They had a significantly low refractive index, suitable for optical applications within the range of 1.6-1.8. The extinction coefficient varied in the range as $1.0-1.7 \times 10^{-5}$ while the absorption coefficient varied varies in the range of $2.1-4.2 \mathrm{~cm}^{-1}$. It was concluded that the thin films were suitable for photonic device applications.
\end{abstract}

Keywords: optical parameters; silver nano-particles; methyl ammonium lead tri-iodide; $\mathrm{CH}_{3} \mathrm{NH}_{3} \mathrm{Pbl}_{3}$; energy band gap.

\section{INTRODUCTION}

Hybrid nonlinear optical materials have received much interest because of their potential applications in optical devices such as optical signal processing, optical switching and optical power limiting [1, 4, 21]. Hybrid materials are currently attracting considerable attention and they are emerging as a new front runner promising materials for optical devices applications owing to their high nonlinearity and ultra-fast responses. These are qualities required in many scientific and material technology device applications [8, 22]. Hybrid materials can be modified when they are doped using suitable metal nanoparticles to display unique optical nonlinearities. In this study, silver nanoparticles were chosen because have excellent unique nonlinear optical properties. Silver as a dopant in methyl ammonium lead tri-iodide, it may contribute to its nonlinear to offer several characteristics advantages like flexibility, ease of fabrication, good transparency or non linear reflectivity, photo and thermal sta- bility $[3,19,24]$. Low fabrication cost may be an added advantage. Scientific developments have developed various techniques to prepare the hybrid films [10, 28, 29]. Among them is solution technique which is a very good, simple, and easy to prepare the hybrid films. It is a technique that was employed to grow silver containing methyl ammonium lead tri-iodide hybrid films at different concentrations. This work reports on the optical properties of $\mathrm{CH}_{3} \mathrm{NH}_{3} \mathrm{PbI}_{3}$, as modified by silver nanoparticles as simulated using the scout software.

\section{THEORETICAL FRAMEWORK}

It's generally accepted that in thin or thick films or wafers, linear absorption coefficient $\alpha$ of an optical medium is usually described by the Lembert-Beer law [7] as (1):

$$
I=I_{0} e^{-\alpha L}
$$


This is acceptable that absorbance $A$ can be defined as (2):

$$
A=I_{0} / I \text {. }
$$

So that Equation (2) can be written as (3):

$$
A=e^{\alpha L} \text {. }
$$

From the Equation (3) absorption coefficient takes the form (4):

$$
\alpha=2.303 \frac{A}{L},
$$

where $I_{0}$ - is the incident light intensity;

$A$ - is absorbance;

$I$ - is the transmitted light intensity;

$L$ - is the length of the absorbing medium.

The extinction coefficient $k$ of the medium sample is directly proportional to the absorption coefficient $\alpha$ according to the following Equation (5):

$$
k=\frac{\alpha \lambda}{4 \pi},
$$

where $\lambda-$ is the wavelength of incident light [15].

Based on this concept, the refractive index $n$ is fundamental parameters as it relates the properties of material as [20]:

$$
n=\left[\frac{1+R}{1-R}\right]+\left[\frac{4 R}{(1-R)^{2}}-\kappa^{2}\right]^{1 / 2},
$$

where the optical reflectance $R$ of the material is given by the relation [15]:

$$
R=\left[1-\left(T e^{e L}\right)\right]^{1 / 2}
$$

Optical conductivity and refractive index of the material relates as [30]:

$$
\sigma_{o p t}=\left[\frac{\alpha n c}{4 \pi}\right]
$$

where $c$ - is the velocity of light, then electrical conductivity $\sigma_{\text {elect }}$ of the material is related to its optical conductivity $\sigma_{o p t}$ as [32]:

$$
\sigma_{o p t}=\left[\frac{2 \lambda \sigma_{o p t}}{\alpha}\right]
$$

Finally, the optical energy gap $E_{g}$ between the valence band $V B$ and the conduction band $C B$ of any material relates to the absorption coefficient $\alpha$ and the incident photon energy $h v$ according to the following relation (10):

$$
(\alpha h v)=C\left(h v-E_{g}\right)^{m}
$$

where $h$ - is the Planck's constant;

$v$ - is the frequency of incident photons;

$C$ - is a constant, its value depends on the transition probability;

$m$ - is an index, its value depends on the type of the electronic transition [12].

\section{METHODOLOGY}

\section{Material and Chemicals}

Silver nitrate $\mathrm{AgNO}_{3}$, hydrazine hydrate, sodium citrate and sodium dodecyl sulphate, doubledistilled de-ionized water, Potassium chloride $\mathrm{KCl}$, zinc nitrate $\mathrm{Zn}\left(\mathrm{NO}_{3}\right)_{2} .6 \mathrm{H}_{2} \mathrm{O}$, copper sulfate $\mathrm{CuSO}_{4} .5 \mathrm{H}_{2} \mathrm{O}$, absolute ethyl alcohol $\mathrm{CH}_{3} \mathrm{CH}_{2} \mathrm{OH}$, ethylene glycol $A R$, sodium hydroxide $\mathrm{NaOH}$, sodium borohydride $\mathrm{NaBH}_{4}$, ascorbic acid $\mathrm{C}_{6} \mathrm{H}_{8} \mathrm{O}_{6}$, trisodium citrate $\mathrm{C}_{6} \mathrm{H}_{5} \mathrm{Na}_{3} \mathrm{O}_{7} .2 \mathrm{H}_{2} \mathrm{O}$, ammonia $\mathrm{NH}_{3}$, poly vinyl alcohol $P V A$ among others.

\section{Preparation of silver nanoparticles}

Sodium dodecyl sulphate and sitrate of sodium were used. Silver nitrate solution containing $1.0 \mathrm{mM}$ and sodium dodecyl sulphate of concentration of $8 \% \mathrm{w} / \mathrm{w}$ was used as a metal salt precursor and a stabilizing agent, respectively. Hydrazine hydrate solution with a concentrate ranging of $1.0 \mathrm{mM}$ and citrate of sodium solution of $1.0 \mathrm{mM}$ was used as a reducing and stabilizing agents. The silver nanoparticles were purified by centrifugation and to remove excess silver ions, the silver colloids were washed at least three times with de-ionized water under nitrogen stream. The obtained dried powder of the nanosize silver was obtained. This solution was diluted by the solvent and samples of solutions 
with different nanoparticles concentrations were obtained. Silver nanoparticles with different concentrations $(0.05,0.06,0.07,0.08,0.09 \mathrm{mM})$ were used. Then, the right quantities were measured and used to coated thin glass substrates and kept for drying for 48 hours at room temperature [25].

\section{Preparation of silver doped $\mathrm{CH}_{3} \mathrm{NH}_{3} \mathrm{Pbl}_{3}$ Thin films}

Thin films of $\mathrm{CH}_{3} \mathrm{NH}_{3} \mathrm{PbI}_{3}$ were prepared by solvent-solvent method as proposed [34]. The precursors was dissolved in a solvent called NMP, then $A g-N P s$ solution were added before coating was done onto a glass substrate. The coated substrate was bathed in diethyl ether $D E E$, a second solvent that selectively grabbed the NMP solvent and whisked it away leaving an ultra-smooth film of crystals.

\section{Characterization of silver doped $\mathrm{CH}_{3} \mathrm{NH}_{3} \mathrm{Pbl}_{3}$ Thin Films}

Transmittance and reflectance was measured by a spectrophotometer within the wavelength range 300-900 nm. Optical parameters were determined through simulation using a computer program (Scout 2.4 software). Analysis was carried out to evaluate the optical properties and the interactions of intrinsic and extrinsic properties of $\mathrm{Ag}-\mathrm{CH}_{3} \mathrm{NH}_{3} \mathrm{PbI}_{3}$ as modified by silver nanoparticles. An uncoated glass slide was used as a reference sample for determining transmittance, reflectance, and absorption to determine other optical constants like band gap and energy losses.

\section{RESULTS AND DISCUSSION}

\section{Crystal Structure}

The crystal structure of was accepted in this work as developed by models in literature [2, 5 , 13]. This formed the base of explaining the observations made in this work. Absorbance $A$, transmittance $T$ and reflectance $R$ was obtained for silver nanoparticles-doped hybrid perovskite thick films at different nanoparticles concentrations recorded over the wavelength range 300-900 nm using the UV-Vis Spectrophotometer. The raw data was plotted to obtain curves using Origin Pro software. The interactions based on simulated data was analyzed and explained.
A crystal structure is composed of a unit cell, a set of atoms arranged in a particular way; which is periodically repeated in three dimensions on a lattice. A crystal structure is a unique arrangement of atoms in a crystal. The obtained doped hybrid perovskite thick films were examined and found to be uniform. Its optical quality was also good. The crystal structure of the precursor methyl ammonium lead tri-iodide is given in Figure 1.

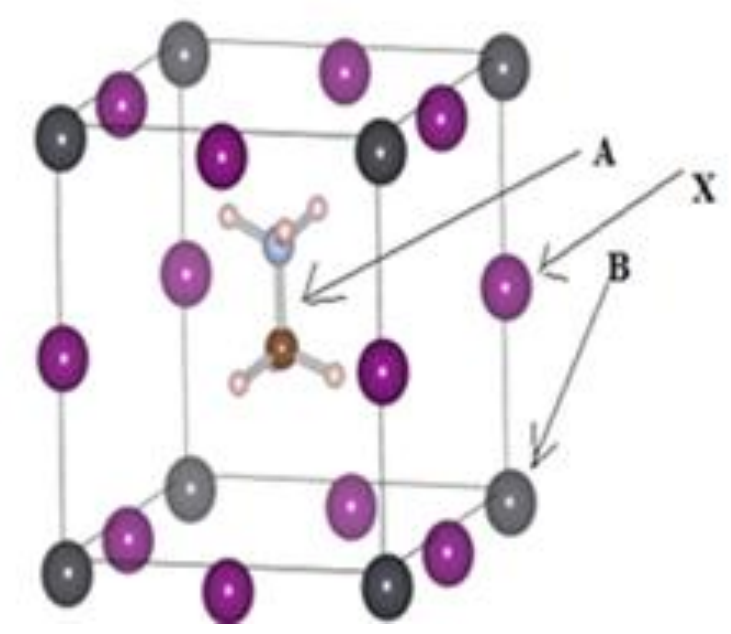

Figure 1 - Chemical structure of $\mathrm{CH}_{3} \mathrm{NH}_{3} \mathrm{Pbl}_{3}$ $\left(\mathrm{A}-\mathrm{CH}_{3} \mathrm{NH}_{3}, \mathrm{~B}-\mathrm{Pb}, \mathrm{X}-\mathrm{I}\right)$

\section{Absorbance $A$}

Although silver nanoparticles at different concentrations were used as follows, it was assumed that the thickness of the films was uniform. In this work, an average large thickness of $89 \mathrm{~nm}$ was obtained. Since absorbance is measure of the capacity of a substance to absorb light of a specified wavelength. It is equal to the logarithm of the reciprocal of the transmittance and therefore, the plot in Figure 2 depicted the variation absorbance against wavelength.

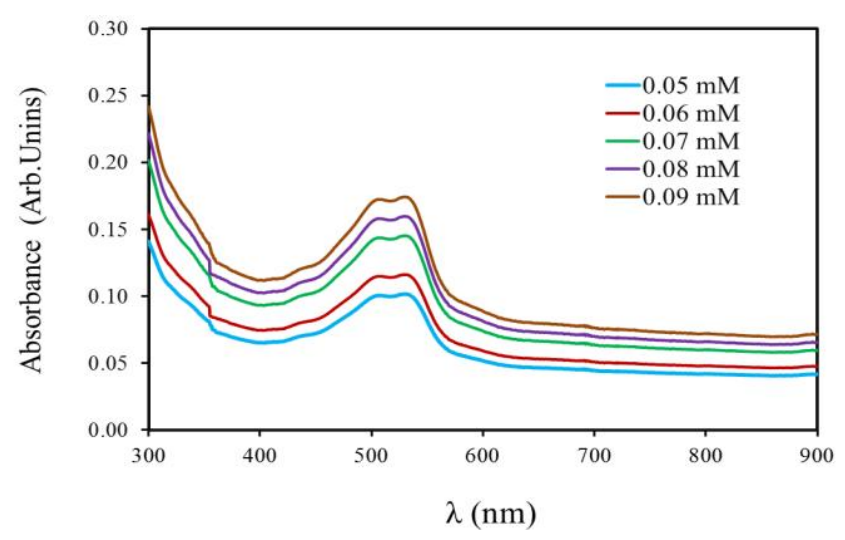

Figure 1 - Absorption spectra of silver-doped hybrid perovskite thick films at different concentrations 
As depicted in Figure 2, the films exhibited strong broad band with peak absorption at around $530 \mathrm{~nm}$ wavelength. This absorption peak was similar to silver nanoparticles peak shown by silver nanoparticles of about $60 \mathrm{~nm}$ nano-size [9, $15,16,23]$. It was also observed that absorbance varied within 10-17\% for all concentrations used.

\section{Transmittance $T$}

Transmittance is the ratio of the radiant energy transmitted through a sample to the radiant energy incident on the surface of the sample. It is the fraction of incident electromagnetic power that is transmitted through a sample, in contrast to the transmission coefficient, which is the ratio of the transmitted to incident electric field. Transmittance reached as high as about $79 \%$ for thick films containing low silver nanoparticles concentration of $0.05 \mathrm{mM}$. However, this decreased as silver nanoparticles concentration increased as depicted by Figure 3.

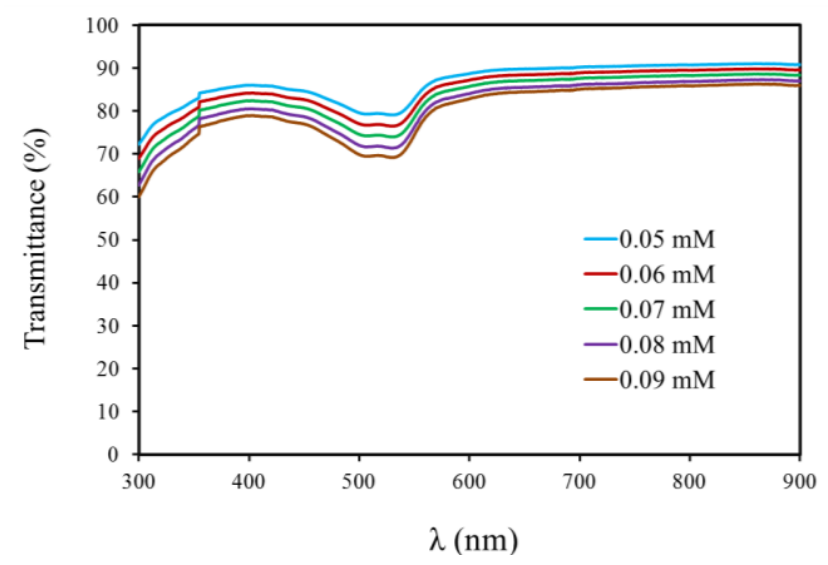

Figure 3 - Absorption spectra of silver-doped hybrid perovskite thick films at different concentrations

\section{Reflectance $R$}

Reflectance of a material defines how effective the surface reflects radiant energy. It is the fraction of incident electromagnetic power that is reflected at an interface. The reflectance spectrum or spectral reflectance curve is the plot of the reflectance as a function of wavelength. The spectrum curves of the reflectance of the thick films had a similar but inverted behavior to those of the absorbance as depicted in Figure 4.

This was therefore attributed to the correlation between reflectance and the absorbance for all concentrations used. It was observed that the value of reflectance $R$ was minima for the low nanoparticles concentration of $0.05 \mathrm{mM}$ at about $6.4 \%$ at visible wavelength region. However, this reflectance increased with increasing silver nanoparticles concentrations till it attained a value of about $9.2 \%$ at $0.09 \mathrm{mM}$ at wavelength $\lambda$ of approximately $545 \mathrm{~nm}$.

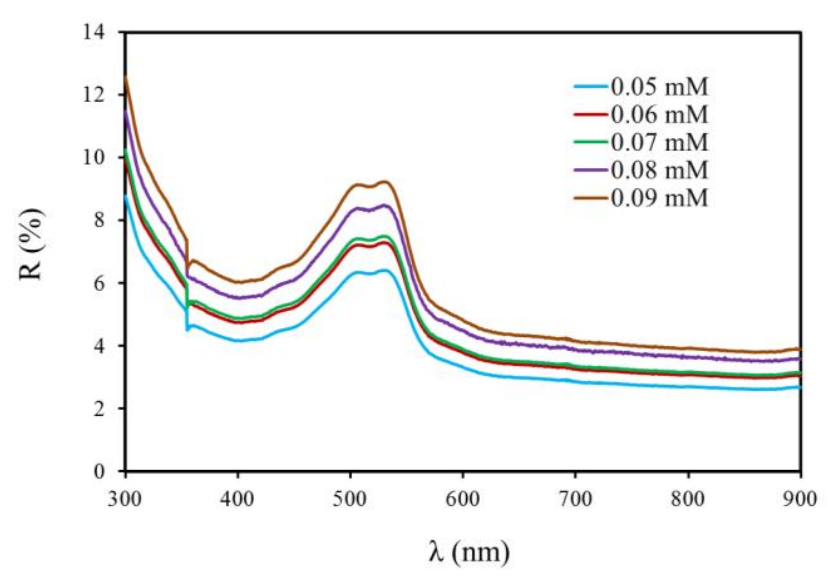

Figure 4 - Reflectance $R$ spectra of the silver-doped hybrid films at different concentrations

\section{Absorption Coefficient $\alpha$}

Absorption in the physics of materials can be defined based on a fractional amount that is proportional to the thickness of the layer. The change in energy as the wave passes through a layer is a constant of the material for a given wavelength and is called its absorption coefficient. The values of the absorption coefficients $\alpha$ was calculated using Equation 3 under the theoretical frame work. The variation plot of $\alpha$, with the photon energy $h v$ at different concentrations is depicted in Figure 5 with the photon energy range of $1.5-5.0 \mathrm{eV}$.

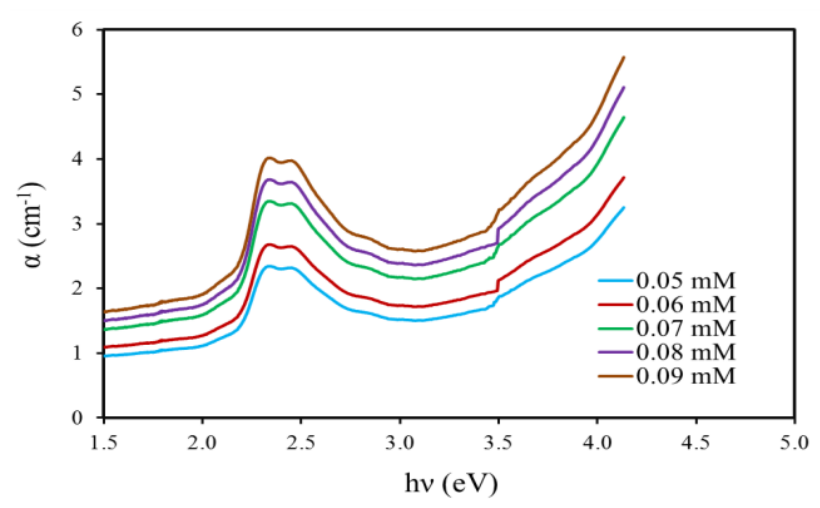

Figure 5 - The absorption coefficient for different silver nanoparticles concentrations 
It was noted that the extinction coefficient $\alpha$ increased with increase the photon energy $h v$. A notable band gap occurred between photon energy $2.4-2.6 \mathrm{eV}$. This was attributed to the presence of silver nanoparticles having influenced the outcome of the absorbance or reflectance of the films [25, 27, 32]. The absorption coefficient varied varies within the range $2.1-4.2 \mathrm{~cm}^{-1}$ depending on silver nanoparticles concentrations.

\section{Extinction Coefficient $k$}

Extinction coefficient is also referred to as molar absorptivity in chemical engineering. It's a parameter that defines how strongly a substance absorbs light at a given wavelength, per mass density or per molar concentration, respectively. Using the calculated and simulated values of the corresponding $\alpha$ and Equation 5, extinction coefficient $k$ was calculated for against incident photon energy $h v$ and the results plotted in Figure 6 for different nanoparticles concentrations.

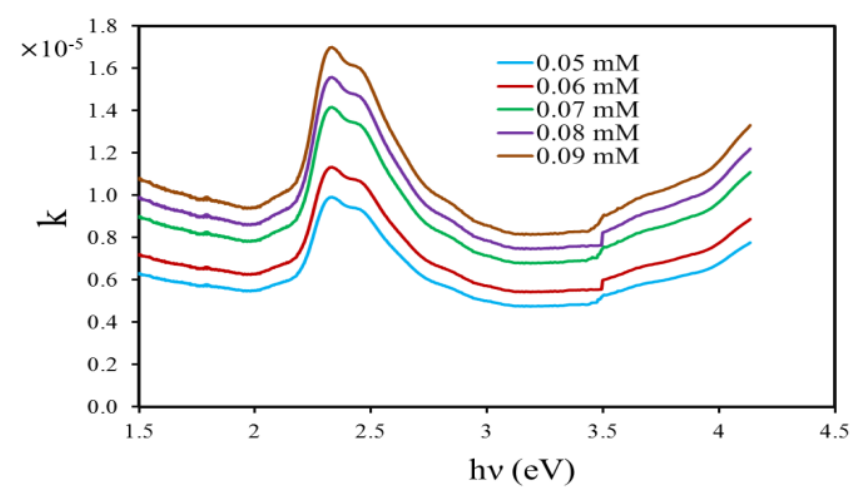

Figure 6 - The extinction coefficient for different nanoparticles concentrations

From the Figure 6, it can be noted that the variation of extinction coefficient was approximately similar to that of absorption coefficient. This was in agreement as this was equally portrayed by the direct relation between the two constants by Equation 5. Therefore, based on the findings, the extinction coefficient varies within the range 1.0$1.7 \times 10^{-5}$.

\section{Refractive Index $n$}

Refractive Index or index of Refraction is a value calculated from the ratio of the speed of light in a vacuum to that in a second medium of greater density [18]. Refractive index variable is symbol- ized by the letter $n$ or $n$ ' in descriptive text and mathematical equations. The variation of the refractive index $n$ with incident photon energy $h v$ for different nanoparticles concentration s plotted in Figure 7 and it can be shown that the refractive index was within the range of 1.6-1.8 for the concentration used.

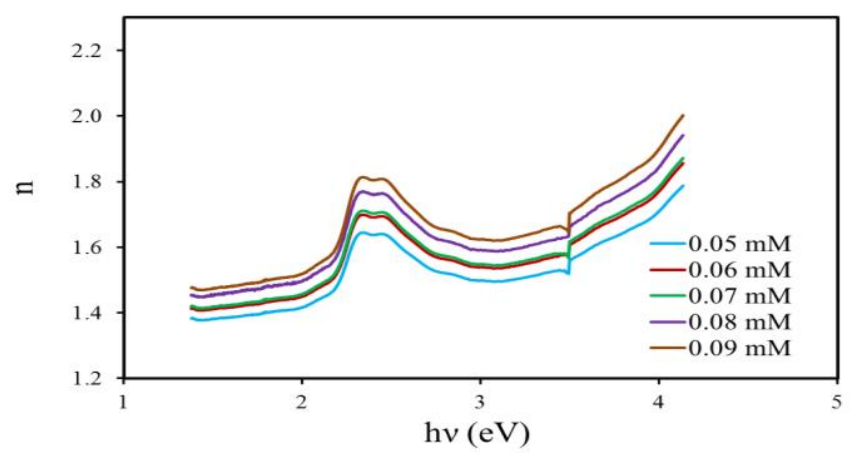

Figure 7 - The refractive index $n$ versus the incident photon energy $h v$ for different nanoparticles concentrations

The maximum obtained refractive index was the photon energy $h v$ of about $2.2 \mathrm{eV}$.

\section{Optical Conductivity $\sigma_{o p t}$ and $\sigma_{\text {elect }}$}

Both optical $\sigma_{\text {opt }}$ and electrical $\sigma_{\text {elect }}$ conductivity were determined by using Equation 8 and Equation 9 respectively and the results obtained were plotted in Figure 8 for optical conductivity and Figure 9 for electrical conductivity respectively for different nanoparticles concentrations.

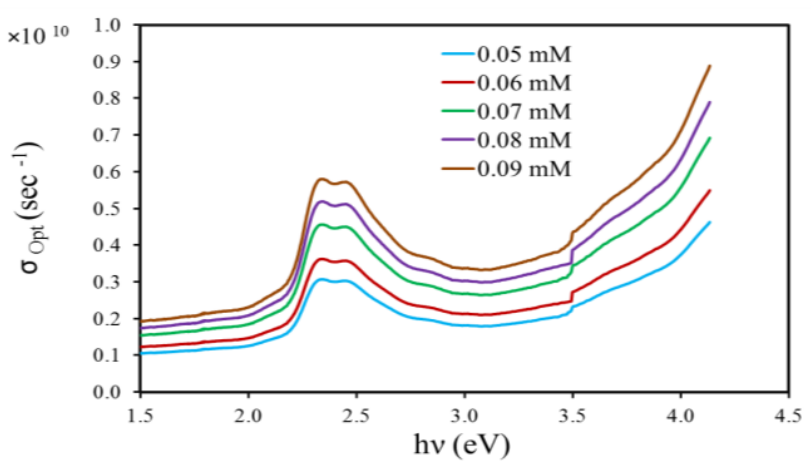

Figure 8 - The variation of the optical conductivity $\sigma_{o p t}$ with the incident photon energy at different concentrations 


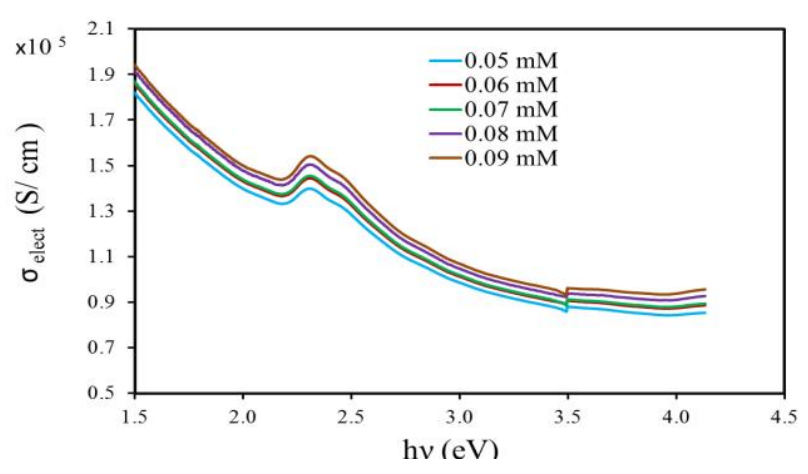

Figure 9 - The variation of the electrical conductivity $\sigma_{\text {elect }}$ with the incident photon energy at different concentrations

Optical conductivity is a measure of electrical conductivity in an alternating field. This allows the dielectric constant as parameter comes into play when analyzing thin films which rules allowed propagations of light into matter. Evaluated optical conductivity refilled that it varied within the range $0.3-0.6 \times 10^{10} \mathrm{sec}^{-1}$.

Electrical conductivity is the measure of a material's ability to allow transport of an electric charge and it is taken as the ratio of the current density to the electric field strength. It is equivalent to the electrical conductance measured between opposite faces of a 1-metre cube of the material under test $[14,26]$. Similarly, the electrical conductivity $\sigma_{\text {elect }}$ was determined and it was found out that it varied within the range 1.4$1.6 \times 10^{5} \mathrm{~S} \mathrm{~cm}^{-1}$. It was concluded that the value of $\sigma_{\text {elect }}$ was noted to be high at the low photon energies and consequently decreased as the incident photon energy $h v$ increased.

\section{Optical band gap $E_{g}$}

In hybrid perovskite semiconductors, electrons are confined to a number of allowed bands of energy, and forbidden bands of energy in other regions. Therefore, the term "band gap" refers to the energy difference between the top of the valence band and the bottom of the conduction band. Electrons are able to jump from one band to another. In this work, the values of the band gap $E_{g}$ was determined form the simulated data through the scout software, without using extrapolated technique where the linear part of the plot $\alpha h v^{1 / 2}$ versus the incident photon energy $h v$ with abscissa $[33,34]$ is used. The simulated band gap was tabulated in table 1 where it was observed that silver nanoparticles increased the band gab [15]. This was explained that increase in absorption coefficient $\alpha$ was not as a result of introducing silver dopant atoms but rather, it was due to the change and realignment of the crystal structure. This was attributed to the crystal defects. It was assumed that the rotation of the $\mathrm{PI}_{3}$ octet may have been restricted to rotate and as a result, the interaction of the Valence band and conduction band may have shifted resulting to increased band gap [6, 14, 17]. From Table 1, it was concluded that the band gap of the $\mathrm{CH}_{3} \mathrm{NH}_{3} \mathrm{PbI}_{3}$ hybrid perovskite film was modified significantly by the presence of silver nanoparticles resulting into a decreased band gap from 1.921-1.832 eV [9, 27, 32].

Table 1 - Band gap $E_{g}$ at different concentrations

\begin{tabular}{|c|c|c|}
\hline Sample & $\begin{array}{c}\text { Silver nanoparticles } \\
\text { concentration, } \mathrm{mM}\end{array}$ & $\begin{array}{c}\text { Energy band } \\
\text { gap } E_{g}, \mathrm{eV}\end{array}$ \\
\hline $\mathrm{A}$ & 0.05 & 1.921 \\
\hline $\mathrm{B}$ & 0.06 & 1.902 \\
\hline $\mathrm{C}$ & 0.07 & 1.883 \\
\hline $\mathrm{D}$ & 0.08 & 1.867 \\
\hline $\mathrm{E}$ & 0.09 & 1.832 \\
\hline
\end{tabular}

This was attributed to a creation or inhalation of both structural and point defects within the optical energy band gap.

\section{CONCLUSIONS}

In this work, silver nanoparticles were used to dope $\mathrm{CH}_{3} \mathrm{NH}_{3} \mathrm{PbI}_{3}$ hybrid perovskite thin films using the solution technique at room temperature. Optical properties were investigated and determined for different silver nanoparticles concentrations where the results showed that the thin films had highest transmittance of about $79 \%$ while its band gap varied from 1.921$1.832 \mathrm{eV}$. Electrical conductivity was 1.4-1.6× $10^{5} \mathrm{~S} \mathrm{~cm}^{-1}$ while optical conductivity varied within the range $0.3-0.6 \times 10^{10} \mathrm{sec}^{-1}$. The refractive index was within the range of 1.6-1.8 which was significantly low for optical applications. Finally extinction coefficient varied in the range $1.0-1.7 \times 10^{-5}$ while absorption coefficient varied within the range $2.1-4.2 \mathrm{~cm}^{-1}$. It was concluded that the thin films grown were suitable for photonic device applications. 


\section{ACKNOWLEDGEMENTS}

The authors appreciate the laboratory technicians of the Department of Pure and Applied Science of Technical University of Mombasa for aid- ing and performing photo spectrometric measurements.

\section{REFERENCES}

1. Abate, A., Saliba, M., Hollman, D. J., Stranks, S. D., Wojciechowski, K., Avolio, R., ... Snaith, H. J. (2014). Supramolecular Halogen Bond Passivation of Organic-Inorganic Halide Perovskite Solar Cells. Nano Letters, 14(6), 3247-3254. doi: 10.1021/nl500627x

2. Agarwal, S., \& Nair, P. R. (2014). Performance optimization for Perovskite based solar cells. In 2014 IEEE 40th Photovoltaic Specialist Conference (PVSC). doi: 10.1109/pvsc.2014.6925202

3. Agarwal, S., \& Nair, P. R. (2015). Device engineering of perovskite solar cells to achieve near ideal efficiency. Applied Physics Letters, 107(12), 123901. doi: 10.1063/1.4931130

4. Ball, J. M., Lee, M. M., Hey, A., \& Snaith, H. J. (2013). Low-temperature processed mesosuperstructured to thin-film perovskite solar cells. Energy \& Environmental Science, 6(6), 17391743. doi: $10.1039 / \mathrm{c} 3 e e 40810 \mathrm{~h}$

5. Burschka, J., Pellet, N., Moon, S.-J., Humphry-Baker, R., Gao, P., Nazeeruddin, M. K., \& Grätzel, M. (2013). Sequential deposition as a route to high-performance perovskite-sensitized solar cells. Nature, 499(7458), 316-319. doi: 10.1038/nature12340

6. Collavini, S., Völker, S. F., \& Delgado, J. L. (2015). Understanding the Outstanding Power Conversion Efficiency of Perovskite-Based Solar Cells. Angewandte Chemie International Edition, 54(34), 9757-9759. doi: 10.1002/anie.201505321

7. Eames, C., Frost, J. M., Barnes, P. R. F., O’Regan, B. C., Walsh, A., \& Islam, M. S. (2015). Ionic transport in hybrid lead iodide perovskite solar cells. Nature Communications, 6, 7497. doi: 10.1038/ncomms8497

8. Eperon, G. E., Burlakov, V. M., Docampo, P., Goriely, A., \& Snaith, H. J. (2013). Morphological Control for High Performance, Solution-Processed Planar Heterojunction Perovskite Solar Cells. Advanced Functional Materials, 24(1), 151-157. doi: 10.1002/adfm.201302090

9. Gardini, D., Christensen, J. M., Damsgaard, C. D., Jensen, A. D., \& Wagner, J. B. (2016). Visualizing the mobility of silver during catalytic soot oxidation. Applied Catalysis B: Environmental, 183, 28-36. doi: 10.1016/j.apcatb.2015.10.029

10. Gonzalez-Pedro, V., Juarez-Perez, E. J., Arsyad, W.-S., Barea, E. M., Fabregat-Santiago, F., Mora-Sero, I., \& Bisquert, J. (2014). General Working Principles of $\mathrm{CH}_{3} \mathrm{NH}_{3} \mathrm{PbX}_{3}$ Perovskite Solar Cells. Nano Letters, 14(2), 888-893. doi: 10.1021/nl404252e

11. Jeon, N. J., Noh, J. H., Kim, Y. C., Yang, W. S., Ryu, S., \& Seok, S. I. (2014). Solvent engineering for highperformance inorganic-organic hybrid perovskite solar cells. Nature Materials, 13(9), 897-903. doi: 10.1038/nmat4014

12. Im, J.-H., Lee, C.-R., Lee, J.-W., Park, S.-W., \& Park, N.-G. (2011). 6.5\% efficient perovskite quantumdot-sensitized solar cell. Nanoscale, 3(10), 4088-4093. doi: 10.1039/c1nr10867k

13. Kojima, A., Teshima, K., Shirai, Y., \& Miyasaka, T. (2009). Organometal Halide Perovskites as VisibleLight Sensitizers for Photovoltaic Cells. Journal of the American Chemical Society, 131(17), 60506051. doi: 10.1021/ja809598r

14. Lang, L., Yang, J.-H., Liu, H.-R., Xiang, H. J., \& Gong, X. G. (2014). First-principles study on the electronic and optical properties of cubic $\mathrm{ABX}_{3}$ halide perovskites. Physics Letters A, 378(3), 290293. doi: 10.1016/j.physleta.2013.11.018 
15. Li, Z., Zhang, M., Cheng, D., \& Yang, R. (2016). Preparation of silver nano-particles immobilized onto chitin nano-crystals and their application to cellulose paper for imparting antimicrobial activity. Carbohydrate Polymers, 151, 834-840. doi: 10.1016/j.carbpol.2016.06.012

16. Lou, X., Pan, H., Zhu, S., Zhu, C., Liao, Y., Li, Y., ... Chen, Z. (2015). Synthesis of silver nanoprisms on reduced graphene oxide for high-performance catalyst. Catalysis Communications, 69, 43-47. doi: 10.1016/j.catcom.2015.05.021

17. Minemoto, T., \& Murata, M. (2014). Device modeling of perovskite solar cells based on structural similarity with thin film inorganic semiconductor solar cells. Journal of Applied Physics, 116(5), 054505. doi: 10.1063/1.4891982

18. Mosconi, E., Amat, A., Nazeeruddin, M. K., Grätzel, M., \& De Angelis, F. (2013). First-Principles Modeling of Mixed Halide Organometal Perovskites for Photovoltaic Applications. The Journal of Physical Chemistry C, 117(27), 13902-13913. doi: 10.1021/jp4048659

19. Nie, W., Tsai, H., Asadpour, R., Blancon, J.-C., Neukirch, A. J., Gupta, G., ... Mohite, A. D. (2015). Highefficiency solution-processed perovskite solar cells with millimeter-scale grains. Science, 347(6221), 522-525. doi: 10.1126/science.aaa0472

20. Noel, N. K., Stranks, S. D., Abate, A., Wehrenfennig, C., Guarnera, S., Haghighirad, A.-A., ... Snaith, H. J. (2014). Lead-free organic-inorganic tin halide perovskites for photovoltaic applications. Energy \& Environmental Science, 7(9), 3061-3068. doi: 10.1039/c4ee01076k

21. Noh, J. H., Im, S. H., Heo, J. H., Mandal, T. N., \& Seok, S. I. (2013). Chemical Management for Colorful, Efficient, and Stable Inorganic-Organic Hybrid Nanostructured Solar Cells. Nano Letters, 13(4), 1764-1769. doi: 10.1021/nl400349b

22. Saoud, K., Alsoubaihi, R., Bensalah, N., Bora, T., Bertino, M., \& Dutta, J. (2015). Synthesis of supported silver nano-spheres on zinc oxide nanorods for visible light photocatalytic applications. Materials Research Bulletin, 63, 134-140. doi: 10.1016/j.materresbull.2014.12.001

23. Sha, W. E. I., Ren, X., Chen, L., \& Choy, W. C. H. (2015). The efficiency limit of $\mathrm{CH}_{3} \mathrm{NH}_{3} \mathrm{PbI}_{3}$ perovskite solar cells. Applied Physics Letters, 106(22), 221104. doi: 10.1063/1.4922150

24. Shabani Shayeh, J., Ehsani, A., Ganjali, M. R., Norouzi, P., \& Jaleh, B. (2015). Conductive polymer/reduced graphene oxide/Au nano particles as efficient composite materials in electrochemical supercapacitors. Applied Surface Science, 353, 594-599. doi: 10.1016/j.apsusc.2015.06.066

25. Snaith, H. J. (2013). Perovskites: The Emergence of a New Era for Low-Cost, High-Efficiency Solar Cells. The Journal of Physical Chemistry Letters, 4(21), 3623-3630. doi: 10.1021/jz4020162

26. Sönnichsen, C., Franzl, T., Wilk, T., Plessen, G. von, \& Feldmann, J. (2002). Plasmon resonances in large noble-metal clusters. New Journal of Physics, 4, 93-93. doi: 10.1088/1367-2630/4/1/393

27. Stranks, S. D., Eperon, G. E., Grancini, G., Menelaou, C., Alcocer, M. J. P., Leijtens, T., ... Snaith, H. J. (2013). Electron-Hole Diffusion Lengths Exceeding 1 Micrometer in an Organometal Trihalide Perovskite Absorber. Science, 342(6156), 341-344. doi: 10.1126/science.1243982

28. Sun, X., Asadpour, R., Nie, W., Mohite, A. D., \& Alam, M. A. (2015). A Physics-Based Analytical Model for Perovskite Solar Cells. IEEE Journal of Photovoltaics, 5(5), 1389-1394. doi: 10.1109/jphotov.2015.2451000

29. Umari, P., Mosconi, E., \& De Angelis, F. (2014). Relativistic GW calculations on CH3NH3PbI3 and CH3NH3SnI3 Perovskites for Solar Cell Applications. Scientific Reports, 4(1). doi: 10.1038/srep04467

30. Wang, U. (2014, September 28). Perovskite Offers Shot at Cheaper Solar Energy. Retrieved from https://www.wsj.com/articles/perovskite-offers-shot-at-cheaper-solar-energy-1411937799 
31. Wei, L., Lu, J., Xu, H., Patel, A., Chen, Z.-S., \& Chen, G. (2015). Silver nanoparticles: synthesis, properties, and therapeutic applications. Drug Discovery Today, 20(5), 595-601. doi: 10.1016/j.drudis.2014.11.014

32. Xiao, Z., Bi, C., Shao, Y., Dong, Q., Wang, Q., Yuan, Y., ... Huang, J. (2014). Efficient, high yield perovskite photovoltaic devices grown by interdiffusion of solution-processed precursor stacking layers. Energy \& Environmental Science, 7(8), 2619-2623. doi: 10.1039/c4ee01138d

33. You, J., Hong, Z., Yang, Y. (Michael), Chen, Q., Cai, M., Song, T.-B., ... Yang, Y. (2014). LowTemperature Solution-Processed Perovskite Solar Cells with High Efficiency and Flexibility. ACS Nano, 8(2), 1674-1680. doi: 10.1021/nn406020d

34. Zhou, Y., Yang, M., Wu, W., Vasiliev, A. L., Zhu, K., \& Padture, N. P. (2015). Room-temperature crystallization of hybrid-perovskite thin films via solvent-solvent extraction for high-performance solar cells. Journal of Material Chemistry A, 3(15), 8178-8184. doi: 10.1039/c5ta00477b 